\title{
CONSIDERACIONES SOBRE EL PRIMER LIBRO DE FUENTES TERMALES EN COSTA RICA
}

\author{
CONSIDERATIONS ABOUT THE FIRST BOOK OF THERMAL SPRINGS IN \\ COSTA RICA
}

\author{
Asdrúbal G. Vargas*1 \& Siegfried Kussmaul ${ }^{2}$ \\ ${ }^{1}$ Centro de Servicio Exploración Subterránea, Área de perforación e inyección \\ Instituto Costarricense de Electricidad (I.C.E.), Apdo. 10032-1000 San José, Costa Rica \\ ${ }^{2}$ Profesor retirado de la Escuela Centroamericana de Geología, Universidad de Costa Rica \\ *Autor para contacto: avargass@ice.go.cr
}

(Recibido: 26/06/2014; aceptado: 15/04/2015)

\begin{abstract}
ABASTRACT: In this work is presented the translation and considerations about the first full catalog with twenty five thermal springs described by A. v. Frantzius in Costa Rica. Since the first publication on hot springs came out incomplete as an article in a medical journal, von Frantzius was given the task of publishing their research through a book in the nineteenth century, with the description of the hot springs in the Reventazón river basin near to Cartago (then the capital of Costa Rica) and in the Candelaria river basin southwestern from San José. The descriptions made in these catalog refer to hot springs located in areas geologically formed by no volcanic rocks or near ancient extinct volcanic apparatus. Frantzius described the geographical and geological characteristics of the places where hot springs emerge and divided them into three groups located in river Reventazón, Candelaria and Grande river basins and Guanacaste region. In eleven hot springs measured the temperature, and determined that the spring with higher temperature was Barranca, while the lowest temperature was Tres Ríos. He proposes a relationship between the topographic elevation of the surface of terrain where the spring emerged and temperature of the water in the thermal spring. He also examined the concentration of several chemical compounds from hot spring Agua Caliente de Cartago.
\end{abstract}

Keywords: Thermal springs, Costa Rica, mineral waters, catalog.

RESUMEN: Se presenta la traducción y consideraciones sobre el primer catálogo completo en forma de libro con veinticinco fuentes termales descritas por A. von Frantzius en Costa Rica. Debido a que la primera publicación sobre fuentes termales salió incompleta en forma de artículo en una revista de medicina, von Frantzius se dió a la tarea de publicar sus investigaciones por medio de un libro, que salió a la luz pública en la segunda mitad del siglo XIX, con la descripción de las fuentes termales más cercanas a Cartago (en ese entonces la capital) y a San José. Las descripciones que se realizan en el catálogo se refieren mayoritariamente a fuentes termales ubicadas en territorios geológicamente formados por rocas no volcánicas o cercanas a antiguos aparatos volcánicos extintos. Describe las características geográficas y geológicas de los sitios donde surgen las fuentes termales y las divide en tres grupos relacionados con cuencas ubicadas al sur de Cartago o de San José. En once fuentes termales midió la temperatura, siendo la fuente termal 
de mayor temperatura la de Barranca, mientras que la de menor temperatura fue la de Tres Ríos. Propone una relación entre la elevación topográfica de la fuente termal y su temperatura. Además midió la concentración química de varios compuestos químicos del agua de la fuente de Agua Caliente de Cartago.

Palabras claves: Aguas termales, Costa Rica, fuentes minerales, catálogo.

\section{INTRODUCCIÓN}

El primer libro sobre fuentes termominerales en Costa Rica (von Frantzius, 1862b), fue publicado en 1862 por la editorial A. W. Schade de Berlín. El libro se logró localizar por medio de la señora Martha Rosen del Instituto Smithsoniano de Washington y se encuentra en una sección especial de la Biblioteca del Congreso de los Estados Unidos. Dicho documento se tradujo del alemán antiguo y consta de 16 páginas con 50 párrafos y 6 notas al pie de página con un entramado y estructura de las oraciones de tipo técnico, y una gran cantidad de vocablos usados en geología y geografía. En las primeras ocho páginas se describe el marco geológico y la ubicación geográfica y a partir de la novena página inicia con la descripción de veinticinco fuentes termales agrupadas por ubicación geográfica y numeradas de manera consecutiva. Primero las ubicadas al suroeste de Cartago, las fuentes del valle del río Grande de Candelaria, las fuentes al suroeste de los Montes del Aguacate y finalmente las fuentes del Golfo de Nicoya, Cañas y Liberia.

La fuente termal de San Cristóbal, ubicada en el valle del río Grande de Candelaria, es descrita de una manera más amplia que las otras fuentes, pues según von Frantzius, es la fuente más importante por su extensión y caudal, con respecto a todas las fuentes conocidas por él en Costa Rica. Considera que podría ser usada como fuente medicinal, aunque no profundiza en este punto. Von Frantzius incluye datos de temperaturas medidas en el agua de las fuentes, en la unidad de medida Reaumur, que se puede transformar a grados Celsius, por medio de la fórmula $5 / 4 *^{\circ} \mathrm{R}$. La fuente termal con la mayor temperatura medida, se encuentra en la margen derecha del brazo oriental del río Barranca, un cuarto de legua (aprox. 1,4 km) aguas arriba del punto donde este brazo se une con el occidental, según la descripción por él indicada. Aunque se incluyen valores de temperatura en las descripciones, las fuentes también las clasifica de manera relativa como fuentes tibias o calientes, tomándose como límite de ambas clasificaciones un valor de temperatura cercano a los $24^{\circ} \mathrm{R}\left(30^{\circ} \mathrm{C}\right)$.

La localización de varias fuentes termales descritas en el libro está referida a algún río conocido como por ejemplo, Grande de Pirrís, Viejo, Grande de Candelaria, Atarrazú, Parrita, Virilla, Machuca y Barranca. Frantzius debió de recurrir a la localización de poblados o ciertas características de los ríos para referenciar espacialmente las fuentes termales. Estas descripciones crean confusión o dificultan la localización de las fuentes actualmente, pues los rasgos morfológicos de algunos ríos han cambiado o el nombre de los poblados ha variado.

En von Frantzius (1862b) se intentó mostrar en Alemania los resultados de las investigaciones realizadas en Costa Rica ya que fue escrito solo en Alemán, dando a conocer las características físico-químicas de las aguas de dichas fuentes de un país poco conocido en Europa como lo era Costa Rica en aquel entonces con la intención de que otros investigadores vinieran a este país e investigaran más adelante las propiedades curativas de dichas fuentes termales.

En ídem no se describen fuentes termales de la vertiente caribe, quizás debido a la falta de caminos y accesos adecuados para llegar a dichas fuentes o a la falta de tiempo y fondos económicos. En la provincia de Guanacaste describe dos fuentes termales, siendo una región que contiene abundantes manifestaciones de fuentes termales (Faillace, 1973). Los materiales geológicos que se mencionan en el documento son, el pórfiro, masas 
de carbonato, alumbre y salitre, cristales de sal, roca caliza y roca intrusiva, depósitos calcáreos y manganeso. El pórfiro es una roca subvolcánica caracterizada por su textura porfídica y generalmente se presenta en forma de diques. El alumbre es el sulfato doble de aluminio y potasio, mientras que el salitre, es considerado como cualquiera de los nitratos minerales que se encuentran en la naturaleza y en especial el nitrato de potasio $\left(\mathrm{KNO}_{3}\right)$. La palabra salitral es una de las más utilizadas en el libro (once veces) y se le denomina al lugar donde se acumula salitre y donde llegaban animales a consumir sal formada de manera natural.

En varias de las descripciones realizadas directamente en el campo utilizó básicamente sus sentidos. Así por ejemplo menciona el sabor ligeramente salado de la fuente de San Cristóbal (No. 9), mientras que para la No. 11, indica que no tenía ningún sabor a sal. En cuanto a la temperatura, señala que para la fuente 15 , el grado de calor es de tal magnitud que la mano se puede mantener en el agua solamente durante un corto tiempo, sugiriendo una temperatura mayor de $45^{\circ} \mathrm{C}$.

\section{Relocalización de las fuentes termales}

A continuación se tratará de ubicar espacialmente las fuentes termales descritas iniciando en la localidad de Orosi, al SE de San José (Figura 1), considerando la información aportada por el geocientífico von Frantzius.

La fuente No. 1, corresponde con las fuentes termales en la desembocadura del río Macho, cerca de la localidad de Río Macho (hoja cartográfica Tapantí, 195500N y 553500 E).

La fuente No. 2, se asocia con las fuentes termales que actualmente se aprovechan para esparcimiento en un balneario de la localidad de Orosi, a $600 \mathrm{~m}$ al Sur y 75 al Este de las instalaciones del antiguo Convento (hoja cartográfica Tapantí, $197400 \mathrm{~N}$ y $552200 \mathrm{E})$.

La fuente No. 3, se ubica $300 \mathrm{~m}$ al Sur y 150 al Oeste del antiguo Convento y se utiliza como fuente de esparcimiento en un balneario (hoja cartográfica Tapantí, $197600 \mathrm{~N}$ y $552200 \mathrm{E}$ ).
La fuente No. 4, brota cerca del río Perlas que desemboca en el río Navarro, (hoja cartográfica Tapantí, $197700 \mathrm{~N}$ y 548800 E).

La fuente No. 5 probablemente se refiere a la fuente que brota en el río Aguacaliente al Sur de Cartago, entre Tejar y San Francisco (hoja cartográfica Istarú).

La fuente No. 6 corresponde a la fuente termal que surge en la quebrada Barahona ubicada cerca de la localidad de Coris de Cartago y del poblado que se denomina Bermejo (hoja cartográfica Istarú 204200 N-538800 E, y está relacionada posiblemente con la falla denominada Guarco en el mapa sismológico y tectónico de Montero (1993) o Agua Caliente en Montero (2003).

La fuente No. 7, corresponde posiblemente con los manantiales del Padre Carazo, captados actualmente por el Instituto Costarricense de Acueductos y Alcantarillados (AyA).

La fuente No. 8 está plenamente identificada al Sur de Desamparados y ha quedado al descubierto aún más hoy en día, luego de que se realizaron excavaciones para la construcción de urbanizaciones. Esta fuente era visitada antiguamente por los ciudadanos de San José para la recreación y en menor medida para usos terapéuticos.

La fuente No. 9, llamada por von Frantzius San Cristóbal y para él la fuente más importante, es al parecer mencionada posteriormente por otros autores (Sáenz, 1971, Sáenz \& Barquero, 1983, Paniagua, 2000), pero ubicada entre San Cristóbal Norte y San Cristóbal Sur (hoja cartográfica Caraigres).

La fuente No. 10 coincide posiblemente con una fuente termal ubicada en la localidad de Santa Elena, al norte del Cerro Bustamante y cercana a Frailes de Desamparados (hoja cartográfica Caraigres). Se ubica aguas abajo de la confluencia de los ríos San Lorenzo y el río San Cristóbal Sur y no como señala von Frantzius entre el Grande de Candelaria y el Tarrazú, pues este último fluye al sur del cerro Bustamante. Esta fuente termal probablemente es una manifestación de la presencia de la falla Patio de Agua, descrita por Arias \& Denyer (1990 a), aunque dichos autores no toman en cuenta este elemento como indicativo de la presencia de dicha falla. 


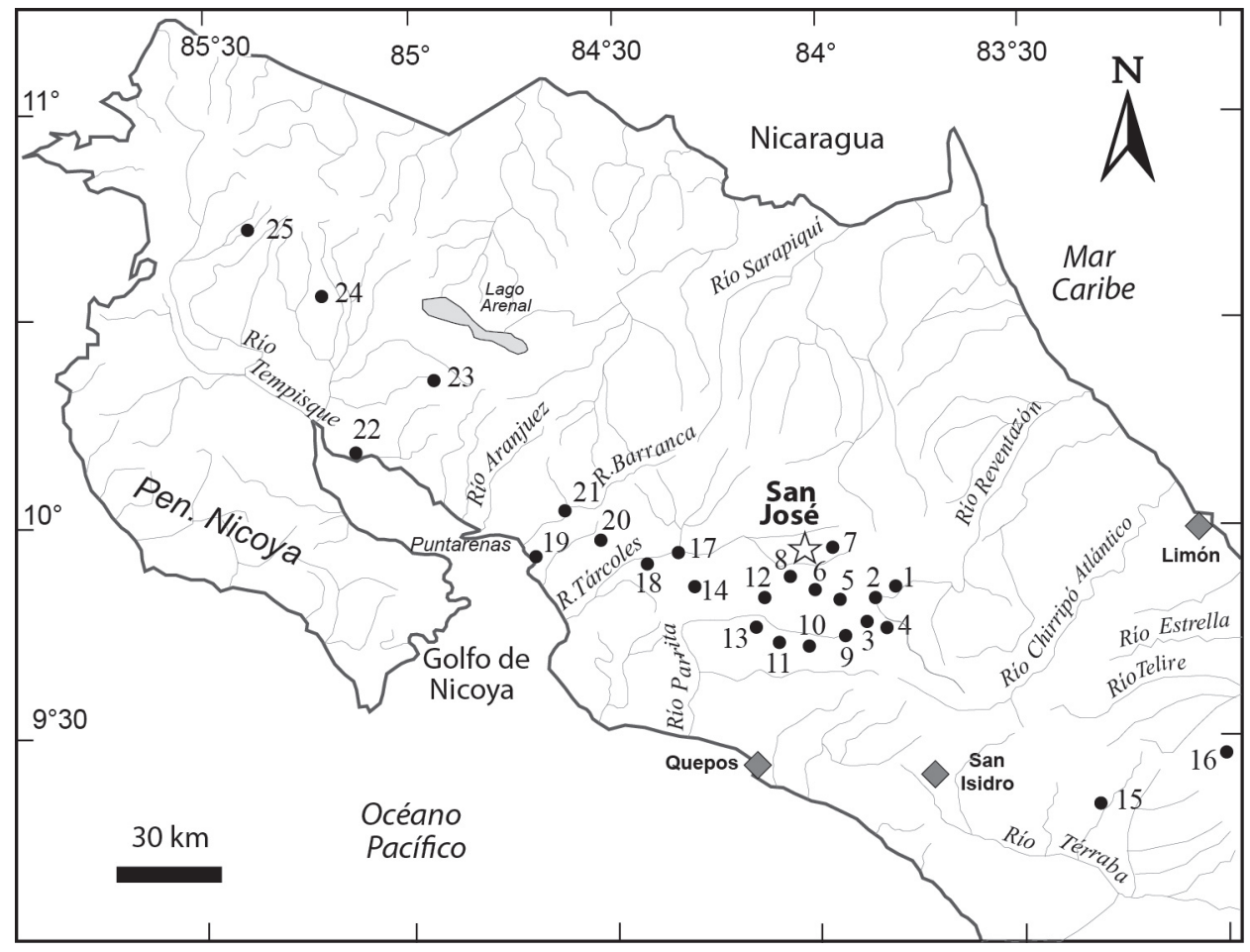

Fig. 1: Ubicación de las fuentes termales descritas. Grupo 1 (fuentes de la 1 a la 8); Grupo 2 (fuentes de la 9 a la 16) y Grupo 3 (fuentes de la 17 a la 25).

La fuente descrita como No. 12, se puede ubicar en el río Alumbre, afluente del río Santa Elena, en la vertiente norte del cerro Bustamante, y al oeste de la fuente No. 10, sin embargo, no se conserva el nombre de Salitral del Rayo como es mencionado originalmente. Estas fuentes ubicadas en el valle del río Grande de Candelaria, vienen a ser un elemento de reconocimiento de un fallamiento, que podría complementar el contexto geoestructural propuesto entre otros por Arias \& Denyer (1991).

En la margen derecha del río Candelaria se encuentra un sitio denominado Cangrejal (hoja cartográfica Caraigres, 512500 y 194500), que posiblemente corresponde con la fuente que menciona von Frantzius como Aguacaliente del Cangrejal (No. 13).

De igual modo la fuente No 14 , se ubicaría al este de Santiago de Puriscal, cercana al pueblo de San Rafael (Hoja topográfica Río Grande y Candelaria, extremo sureste), en el río Viejo, afluente del Tabarcia, aunque no hay nombres geográficos que indiquen la presencia directa de dichos manantiales.

La fuente No. 17, se ubicaría en la hoja topográfica Río Grande. Muy cerca se encuentra la intersección de la falla La Garita con una falla hipotética según Arias \& Denyer (1990b), aunque no hay descripciones geográficas que destaquen la presencia de dichas fuentes. Es decir no está reportada en los trabajos subsiguientes del siglo XX, de las fuentes termales de Costa Rica.

La ubicación geográfica de la fuente No. 18, es más sencilla de hallar en la hoja topográfica río Grande, ya que continuando río abajo sobre el río Grande, después de la fuente anterior, se llega a un sitio denominado Bajo Alumbre, muy cerca de la confluencia de la quebrada Salitral con el río Grande de Tárcoles. Además, al sur del Bajo Alumbre existe un hito topográfico llamado San Pablo y un cerro con el mismo nombre y al norte una quebrada llamada Santo Domingo, los cuales concuerdan con los nombres de los poblados señalados por von Frantzius hace 153 años a la fecha (2015). 
Con respecto a la fuente No. 20, es preciso señalar que la observación detenida del área que comprende las nacientes del río Machuca, ubicada en las hojas cartográficas Barranca, Río Grande y Naranjo (1: 50 000), permite identificar la presencia de varias caleras, es decir sitios donde se explotan depósitos de rocas calcáreas para extraer carbonato de calcio. Estas canteras concuerdan con lo señalado por von Frantzius, es decir a 5,5 $\mathrm{km}$ al norte de San Mateo, en las nacientes del río Machuca y con la presencia de masas calcáreas. Por otro lado, es de mencionar que a $11 \mathrm{~km}$ al noroeste de San Mateo existe un sitio denominado Salitral y existe también una quebrada con el nombre de Salitre, que dan la idea de la presencia de aguas termales, pero esto ocurre en la cuenca del río Jesús María.

Existe una fuente termal cerca de la planta hidroeléctrica Nagatac (hoja cartográfica Miramar, coord. 226500-477500), posiblemente relacionada con la fuente No. 21, precisamente a $11 \mathrm{~km}$ al Noreste de Esparza, en las márgenes del río Barranca, mencionadas por Sáenz (1971), Sáenz \& Barquero (1983). Sin embargo, no está claro a qué llama von Frantzius el brazo oriental y brazo occidental del río Barranca, lo cual genera confusión sobre la ubicación precisa de esta fuente. Pese a ello, la misma era conocida ya en tiempos de la colonia española, pues en su artículo de 1873 , se menciona que en una crónica de dos misioneros del año 1756, estos indicaban la existencia de un yacimiento de sal, ubicado al norte de Esparza, relacionado posiblemente con una fuente termal. Desgraciadamente, von Frantzius no deja mayores referencias sobre este documento que permitan acceder a estas crónicas.

No hay evidencias geográficas claras sobre la fuentes termales, que según von Frantzius aparecen entre la desembocadura de los ríos La Palma y Abangares (No. 22). Las únicas fuentes referidas se ubican, cerca de Colorado de Abangares (hoja cartográfica Abangares), citadas por Sáenz, (1971) y Sáenz \& Barquero (1983).

Con respecto a la fuente No. 23, según von Frantzius se ubica al este del poblado Las Cañas, en las nacientes del río Abangares. En este sector existen varios nombres que dan la impresión de estar relacionadas con fuentes termales, como el río Aguacaliente, que desemboca en el río Abangares (hoja cartográfica Juntas 3246 IV), cerca de la localidad de Juntas. Sáenz \& Barquero (1983), mencionan varias fuentes termales dentro de la hoja cartográfica Juntas (3246 IV), ubicadas al noroeste de la localidad de Las Juntas, en la quebrada la Luz y en Santa Lucía.

En referencia a la fuente No. 24 del artículo de 1862 situada por von Frantzius en Salitral, existe efectivamente una fuente al noreste de Bagaces, en un sitio denominado con dicho nombre (hoja cartográfica Tierras Morenas). Sin embargo, la distancia no coincide con la señalada por von Frantzius, pues el sitio se encuentra a $6 \mathrm{~km}$ y el menciona tan solo $1 / 3$ de legua, lo que equivale aproximadamente a $1,7 \mathrm{~km}$. No obstante, en su artículo de 1873 al parecer von Frantzius rectifica al mencionar, que el profesor Karl von Seebach (Von Seebach, 1865) encontró un sitio llamado Salitral a 3 leguas [aprox. 15,5 km] de Miravalles, en el camino hacia Bagaces y que existía una fuente termal a $1 / 2$ legua $[2,5 \mathrm{~km}]$ al este de este sitio. Esta ubicación sí concuerda con la señalada para las fuentes termales mencionadas, por Faillace (1973), en la compilación de fuentes termales de la provincia de Guanacaste y por Sáenz \& Barquero (1983) y Paniagua (2000).

La fuente termal identificada No 25, situada por von Frantzius en la hacienda la Cueva, podría estar ubicada a $10 \mathrm{~km}$ al noroeste de Liberia (hoja cartográfica Ahogados, coord. 369-296,5), en la hacienda la Cueva, no obstante, que no hay nombres geográficos que identifiquen la presencia de dicha fuente y no está identificada en los trabajos sobre fuentes termales del siglo XX.

\section{LAS FUENTES TERMOMINERALES EN COSTA RICA}

\section{Alexander von Frantzius}

Las fuentes termominerales en Costa Rica se pueden interpretar como una continuación de la notable serie de manantiales termales minerales que se encuentran en Venezuela en una extensión de 150 millas desde la precordillera de Paria hasta Mérida [Ver v. Humboldt: Viajes a las regiones 
equinociales (tropicales), 1818 Parte II pág.170, Parte III pág. 44 y parte IV pág. 103] las cuales en Costa Rica ocurren a la misma latitud $\left(10^{\circ}\right.$ latitud N) como en Venezuela e igualmente como en dicho lugar, aquí aparecen en terrenos no volcáni$\cos$. Ellas empiezan en una longitud geográfica de 13 grados más hacia el $\mathrm{W}$ y se extienden en una extensión de aproximadamente 13 millas paralelo a la latitud mencionada de $\mathrm{E}$ a $\mathrm{W}$ y solo se alejan muy poco de esta latitud.

Estas fuentes termales, de las cuales conozco hasta el momento veinticinco, se encuentran en las montañas de Candelaria, Dota y Aguacate, así como en la cordillera de Guanacaste, territorios formados por granitos, pórfidos o rocas dioríticas y donde las fuentes aparecen a los pies de las cordilleras, a las orillas de los ríos y en los lugares más profundos, en las fracturas y grietas producidas por los temblores volcánicos. De esta manera, así como también debido a otras características peculiares, testifican que no se forman como los manantiales fríos de agua dulce a partir de precipitaciones atmosféricas como fuentes meteorológicas, sino que ellas salen de profundidades relativamente grandes como fuentes geológicas desde el interior de la Tierra.

Igual como en Europa, donde aparecen en las cercanías de focos volcánicos extintos, exhalaciones de gases con ácido carbónico como resultado de las actividades volcánicas remanentes. Igualmente se encuentran las mismas manifestaciones en Costa Rica bajo similares condiciones, pero a una escala mucho mayor. El agua subterránea está sometida a una alta presión atmosférica, y es capaz de disolver determinadas substancias de las rocas que penetra produciéndose aguas minerales alcalinas.

Las cordilleras mencionadas anteriormente se elevan tanto al sur como al $\mathrm{W}$ de los volcanes extintos Poás, Barba e Irazú, separados de estos por una planicie ubicada a los pies de los mismos volcanes, la cual se extiende en promedio de 3 hasta 4 leguas y en ciertos lugares hasta de 5 a 6 leguas. Por consiguiente, se encuentran en el interior de la mencionada cordillera las fuentes existentes a una distancia entre 12 hasta 15 leguas de los volcanes ubicados inicialmente [en una publicación anterior "Contribución al conocimiento de los volcanes de Costa Rica" [N.T. (von Frantzius, 1861)] mencioné que algunos de los cerros denominados "Volcán" en Costa Rica probablemente no son volcanes].

La temperatura de las fuentes termales que tuve la oportunidad de investigar sobrepasa en la mayoría de casos significativamente la temperatura promedio del lugar donde se encuentran. Encontré temperaturas muy variables, desde 23,2 hasta $55,6^{\circ} \mathrm{R}$ [ ${ }^{\circ} \mathrm{R}$ : Reaumur: $\left.1^{\circ} \mathrm{R}=1,25^{\circ} \mathrm{C}\right]$. Notable es la particularidad, observada también en otros lugares, que la temperatura de las fuentes termales parece que disminuye con respecto a la altura del lugar sobre el nivel del mar. La temperatura más baja de $23,2^{\circ} \mathrm{R}$, la encontré en la fuente de Tres Ríos que se ubica a la mayor elevación, a aproximadamente 3800 pies de Paris sobre el nivel del mar, en donde la temperatura media del lugar es de aproximadamente 16 grados R; mientras que la fuente de Barranca, se encuentra a una elevación de aproximadamente 800 pies Paris sobre el nivel del mar es la más caliente y presenta una temperatura de $55,6^{\circ} \mathrm{R}$. Parece que la alta temperatura original de algunas de estas fuentes se reduce debido a que incorporan una cantidad variable de agua meteórica.

Desgraciadamente solamente conocemos la cantidad de los componentes minerales de una sola fuente, la de Aguacaliente en Cartago. El análisis químico de su agua fue realizado por el conde F.G. v. Schaffgotsch y se obtuvieron los siguientes resultados encontrándose en 16 onzas [1 onza $=29,2 \mathrm{~g}, 1 \mathrm{Gran}=0,81 \mathrm{~g}]$ de agua:

\begin{tabular}{|c|c|}
\hline Ácido sulfúrico potásico & $=1,15$ Gran \\
\hline Ácido sulfúrico sódico & $=4,78-$ \\
\hline Cloruro de sodio & $=7,55-$ \\
\hline Bicarbonato sódico & $=1,11-$ \\
\hline Bicarbonato cálcico & $=3,28-$ \\
\hline Bicarbonato magnésico & $=0,86-$ \\
\hline Sílice & $=0,47-$ \\
\hline Pérdida & $=0,54-$ \\
\hline
\end{tabular}

Además, el agua contiene bicarbonato libre, probablemente más de 2,35 granos, pero en la muestra que se envío no se puede determinar exactamente. 
En esta fuente termal, la cual brota a solo pocos pasos de la orilla del río del mismo nombre y que fluye inmediatamente en él, el agua no se estanca o se evapora como en las otras fuentes, que de esta manera muestran las sales y demás minerales contenidos en el agua. Sin embargo, el análisis del agua de esta fuente demuestra un alto contenido de sal común, lo cual coincide con muchas otras fuentes termales, las cuales por la formación de los llamados "salitrales" evidencian el gran contenido de estas sales. El contenido en sal común, se evidencia solo en pocas de las fuentes visitadas por mí por medio de un débil sabor salado, es para muchas sin embargo de tal importancia, que se encuentran delgadas costras de sal sobre las rocas que afloran en los sectores de las descargas de agua termal. Justamente esta característica fue la que llamó la atención de la población sobre esta clase de fuentes. Uno sabe muy bien, que la crianza de ganado es una de las fuentes de ingresos más importantes en Costa Rica y el consumo amplio de la sal es extremadamente importante para el buen desarrollo del ganado vacuno. Por eso la cantidad de sal común utilizada para alimentar el ganado vacuno es mucho mayor que la cantidad utilizada por la población para sus comidas. Las fincas en las cuales se encuentran estos yacimientos de sal son muy buscadas por parte de los propietarios del ganado vacuno.

La sal que se ha encontrado en esas fuentes en varias ocasiones llamó la atención de que grandes yacimientos de sal pudieran estar presentes en el subsuelo. Ya en el año 1756 algunos misioneros que desde Esparza ingresaron en la cordillera ubicada al norte con el fin de cristianizar a los salvajes aborígenes Guatusos que allí vivían, creyeron haber encontrado mineral de sal, cuando en el camino de regreso pasaron por la fuente termal de Barranca. En los años siguientes varias veces se trató de buscar de nuevo esa supuesta mina de sal pero sin éxito. Cuando yo conocí esa fuente termal en el año 1860 , me convencí que el "mineral de sal" que encontraron los misioneros según las referencias del lugar, no podría ser otra cosa que la fuente termal de Barranca. Debido a que esta fuente brota de rocas porfiríticas y de que en una gran área cercana a la fuente solamente se observan rocas plutónicas, el agua muy caliente no tiene ningún sabor a sal. Cuando las aguas realmente pasarían a través de un yacimiento de sal debería aparecer a la luz del día como agua muy salada, por lo tanto aquí no se puede hablar de un yacimiento de sal existente en la profundidad.

El hecho de que a pesar del contenido de sal tan bajo se cristalice una cantidad relativamente grande en la superficie, es fácilmente comprensible si se toman en cuenta tres factores que favorecen enormemente el proceso de evaporación. Estos son el calor del aire debido al clima, los vientos alisios que soplan en el verano durante cinco meses casi continuamente y principalmente la sequía de la atmósfera [En Alajuela la humedad relativa de la atmósfera era según mis observaciones en Abril de 1854, al final de la época seca, solamente $55 \%$, mientras que en octubre del mismo año, al final de la época lluviosa, era de 93\%].

Sería muy importante para el bienestar del país, disponer de depósitos de sal en el interior, no solo porque la producción de sal en las salinas en la costa del océano, no es suficiente para suplir la demanda de la población, sino también porque la condición insalubre del clima de la costa y fiebres malignas anualmente provocan varios muertos. Sin embargo, se debe de desistir completamente de la idea de que el contenido de sal en las fuentes termales podría ser considerado como una señal de la presencia de depósitos ocultos de sal. Precisamente el hecho de que la fuente antes mencionada, que brota en medio de rocas plutónicas, mientras que las verdaderas fuentes termales saladas siempre ocurren en formaciones geológicas de origen marino es el motivo por el cual debemos renunciar completamente a la esperanza de encontrar yacimientos de sal en las cercanías de estas fuentes. Además, también es necesario tomar en cuenta que aquellas fuentes, las cuales forman "salitrales" y que por eso se supone que tengan un contenido de sal común, en realidad no contienen esa sal disuelta en el agua. Al ganado le gusta lamer también otras sales, por lo tanto, cuando las vacas buscan tales salitrales esto no es de ninguna manera una prueba de la presencia de sal común. En la fuente de San Cristóbal, donde 
gruesas costras de sal cubren los alrededores de las descargas de agua termal y donde yo suponía un significativo contenido de sal, por medio de los análisis químicos no encontré absolutamente ningún indicio de cloruro de sodio, o de algún otro compuesto de cloruro, sino solamente sales de ácido sulfúrico.

La presencia de bicarbonato de calcio, que muestran los análisis de la fuente de Aguacaliente, se nota también en algunas otras fuentes, y además en cantidades mucho mayores, lo que pone de manifiesto los extensos depósitos de carbonato de calcio en las proximidades a las fuentes. Muy importante es el caso de la fuente de Navarro, la de San Cristoval [sic], la del río Machuca y la de Barranca, a diferencia de la mayoría de las otras fuentes donde no se encuentra ninguna prueba de ello. En el caso de Navarro y Aguacaliente, se encuentran en la otra orilla del río, afloramientos de carbonatos fosilíferos, así que aquí no hay ninguna duda de donde estas fuentes adquieren el contenido de carbonato de calcio.

Las sales solubles en el agua son el cloruro de sodio y generalmente las sales formadas por el ácido sulfúrico, entre las cuales de nuevo predomina el ácido sulfúrico sódico. Por cierto, también se han encontrado otras sales de ácido sulfúrico en las cercanías de estas fuentes termales, como por ejemplo ácido sulfúrico cálcico en Desamparados, formando drusas con cristales de yeso, las cuales se encuentran en la capa superior de humus; también ácido sulfúrico ferroso y alumbre este último se encuentra en varias fuentes en tal cantidad que las localidades cercanas han recibido dichos nombres, como por ejemplo el río del Alumbre en el Candelaria, el Paso del Alumbre cerca de San Pablo en el río Grande y otros más. Sin embargo, parece que estas sales se formaron por la descomposición química y por lo tanto no pertenecían a los componentes originales del agua mineral.

Muy notable es el elevado contenido de ácido carbónico libre, que tiene la mayoría de fuentes, lo cual se manifiesta en algunas por medio del ascenso continuo, en otras por el ascenso intermitente de grandes burbujas de gas, y que da la apariencia de que estuvieran en ebullición. A estas fuentes se les llama "hervideros".
Esto provoca en la mayoría de la gente un gran asombro, ya que parece que estas fuentes tienen un calor de ebullición, sin embargo no se logra cocinar un huevo, para lo cual, como se sabe, es necesario que la temperatura sobrepase los 48,8 grados $\mathrm{R}$, lo cual solo lo he encontrado en tres de las fuentes evaluadas.

Me pareció interesante que en la fuente de Navarro no se percibe la producción de gases. Considerando que esta fuente presenta un elevado contenido de bicarbonato de calcio, es probable que todo el ácido carbónico este ligado al calcio y por consiguiente no queda suficiente ácido carbónico libre.

Curioso es que las fuentes de Costa Rica, al igual que aquellas de Venezuela, presenten una amplia diferencia en relación al grado de temperatura, contenido mineral y gases contenidos en ellas.

A pesar de que debido el alto contenido en sales alcalinas y la elevada temperatura muchas de estas fuentes son aptas como fuentes terapéuticas, solo se ha hecho una limitada aplicación de estas fuentes en Costa Rica. Casi la única fuente que se utilizaba de esta manera era la de Aguacaliente ubicada a poco menos de una hora de Cartago, la antigua capital del país. Esta fuente fue protegida por los perspicaces españoles con una muralla, de la cual sin embargo, uno ahora solo nota algunos restos. Muy extraño es que la fuente que se encuentra en Desamparados, igualmente ubicada a una hora de San José, la actual capital, casi no se usa como fuente curativa, aunque ella, en relación con su contenido mineral y su temperatura, no es muy diferente a la mencionada anteriormente. La avanzada educación de la población debería instruir sobre el aprovechamiento de las fuentes termales curativas en general y especialmente sobre las ventajas de estas fuentes termales que se ubican cerca de los centros de población. Pero le hace mucha falta a los habitantes de Costa Rica, como a toda la raza hispanoamericana, la voluntad de la construcción de instalaciones de interés común. Es muy probable que la población de Costa Rica carezca todavía por mucho tiempo del beneficio de instalaciones de balnearios termales bien equipados, lo cual irá en su propio perjuicio, desaprovechando lo que la naturaleza le ha dado con mano bondadosa. 
Como ya lo mencioné al principio, las fuentes termales en Costa Rica se las encuentra uno siempre en el fondo de gargantas o a la orilla de cauces profundos. Para el listado de las diferentes fuentes, lo más razonable es describirlas de acuerdo con las cuencas en las cuales se encontraron.

1. En el Valle del río Macho, aguas abajo conocido con el nombre de Reventazón, se encuentra la fuente termal ubicada más al Este, en la hacienda ganadera del fallecido General Montero[Ver. Ausland 1860 "El convento misionero de Orosi]. En una planicie inclinada hacia el río con una extensión aproximada de 50 pasos, brota agua caliente en diferentes puntos bajo rocas y raíces de árboles. Donde brota el agua más profusamente alcanza una temperatura de $44,7^{\circ} \mathrm{R}\left[55,9^{\circ} \mathrm{C}\right]$ y en otros sitios solo $40^{\circ} \mathrm{R}\left[50^{\circ} \mathrm{C}\right]$. Al evaporarse el agua deposita sales sobre las rocas. Espectacular es aquí la presencia de oscilatoria [Esa alga de agua dulce se encuentra también en la fuente de Mariara en Venezuela. S. Humboldt a.a.O. III pág. 145 ] verde oscura, la cual se encuentra casi siempre en las restantes fuentes termales y que vive muy cerca de las salidas de los fluidos, donde el agua aún conserva su alta temperatura original, como también aguas abajo en el agua fría.

2. Unos cientos de pasos al este del edificio del convento de Orosi en una pequeña hondonada de la planicie, surge del suelo una fuente termal con una significativa generación de gases, cuya agua tenía una temperatura de $41,2^{\circ} \mathrm{R}\left[51,5^{\circ} \mathrm{C}\right]$. Ya a una cierta distancia se percibe el olor característico de la fuente. Aunque el agua no tenía sabor, si se notaban ciertas evidencias de sales en forma de cristales sobre las piedras que se sobresalen del agua.

3. Directamente al pie de los cerros, que limitan el valle de Orosi al sur, a unos cientos de pasos del edificio del convento surge una fuente termal con un fuerte chorro de agua tibia, cuya temperatura alcanzó $27,6^{\circ} \mathrm{R}\left[34,5^{\circ} \mathrm{C}\right]$. Sin embargo, no se puede decir mucho sobre su contenido mineral, porque no hay precipitados y el agua no tiene ningún sabor. Debido a la agradable temperatura del agua esta fuente, que forma una poza natural, se ha utilizado como balneario.

4. A media hora de la ciudad de Orosi, cerca de la hacienda Navarro en la margen izquierda del río del mismo nombre, aparecen dos fuentes termales las cuales están separadas entre sí por unos 500 pasos. La temperatura de la fuente oriental alcanza $25,8{ }^{\circ} \mathrm{R}\left[32,3{ }^{\circ} \mathrm{C}\right]$. Esta fuente brota a los pies de una loma compuesta por rocas porfiríticas, y alrededor se encuentran grandes depósitos de caliza en forma de estalagmitas y al otro lado del río se encuentra aflorando una caliza azul grisácea con fósiles de moluscos que se explota en un tajo.

5. A poco menos de una hora al sur de Cartago, en la margen derecha del río Agua Caliente, se encuentra la fuente de agua termal más conocida entre las fuentes termales de Costa Rica, cuya temperatura alcanza $40{ }^{\circ} \mathrm{R}\left[50,0{ }^{\circ} \mathrm{C}\right]$. Ella surge a pocos pasos de la orilla del río, a los pies de un cerro formado de caliza, y también se la explota en una cantera. El análisis químico del agua ya fue mencionado anteriormente.

6. Al suroeste de Cartago, en dirección del poblado indígena de Tobosi, se encuentra una fuente termal caliente, en una depresión con forma de embudo, sobre la Sabana grande de Coris. Muy cerca existe un lugar al cual se le da el nombre de Salitral, probablemente debido a que la evaporación del agua estancada causa el fuerte contenido en sal.

7. A poco más de una milla de San José, en dirección hacia el este, se encuentra en una plantación de café perteneciente a Manuel Carazo ubicada en la localidad de Tres Ríos, una fuente termal tibia con generación de gases que alcanza una temperatura de $23,2^{\circ} \mathrm{R}\left[29,0^{\circ} \mathrm{C}\right]$.

8. En dirección sureste del poblado de Desamparados, a una hora de San José, se encuentra al pie de un cerro formado por una roca de tipo pórfido, en el lugar más profundo de una pradera pantanosa, una especie de estanque en cuyo borde meridional brota agua caliente. En mayo de 1859 su temperatura alcanzó $37{ }^{\circ} \mathrm{R}\left[46,3{ }^{\circ} \mathrm{C}\right]$, mientras que en junio de $1860,36,5^{\circ} \mathrm{R}\left[45,6^{\circ} \mathrm{C}\right]$. Las rocas y hojas, que sobresalen del agua estaban cubiertas parcialmente con cristales de sal. Esta fuente se utiliza de vez en cuando como balneario y lleva el nombre de Aguacaliente y Salitral de los Desamparados.

Ahora continuamos con un segundo grupo de fuentes ubicadas más al sur, las cuales se encuentran en el valle del Río Grande y de Candelaria.

9. La más oriental de estas es la fuente termal de San Cristóval [sic]. Por su extensión y caudal 
es la fuente termal más importante que conocí en Costa Rica. Con respecto a la temperatura ella casi se acerca a la fuente de Barranca. Por su posición [aproximadamente 4 leguas de San José] y el clima saludable de la región sobresale de las demás y es considerada de gran importancia, para ser captada y usada como fuente terapéutica en un futuro.

Los manantiales se encuentran en el extremo occidental del poblado, en la margen izquierda del río Candelaria, que fluye en un profundo valle, a ambos lados de un riachuelo de agua dulce, el cual por medio de una pequeña garganta drena hacia el río Candelaria, el cual capta una parte del agua mineral y adquiere una temperatura de $15,4{ }^{\circ} \mathrm{R}$ $\left[19,25^{\circ} \mathrm{C}\right]$. A lo largo de toda la orilla del río, en una extensión de 300 a 500 pasos, se encuentran en las laderas de la loma rocas cristalinas verdosas grandes masas de caliza porosa y muy frágil, cuyo origen se debe al agua mineral. En aquellos sectores donde la quebrada fluye por la caliza, se van formando gradas regulares de tal manera, que se tiene la impresión de estar observando una escalera artificial.

Inmediatamente en el lado este del pequeño riachuelo se encuentran las fuentes principales, las cuales se caracterizan por su alta temperatura y su fuerte contenido calcáreo, teniendo la temperatura del agua un valor de $53,4^{\circ} \mathrm{R}\left[66,75^{\circ} \mathrm{C}\right]$ e incluso en un punto hasta $54,0^{\circ} \mathrm{R}\left[67,5^{\circ} \mathrm{C}\right]$. El agua tiene un ligero sabor salado y brota en gran cantidad con un burbujeo periódico de una pared calcárea cubierta de cristales de sal de color blanco nieve. A ambos lados, tanto al este como al oeste, aproximadamente a 50 pasos de distancia de las fuentes principales, se encuentran otros dos lugares donde surge agua caliente. En la fuente oriental están ausentes los depósitos calcáreos por completo. El agua brota aquí en varios lugares entre las rocas con la exhalación de gases y tiene una temperatura de $40^{\circ} \mathrm{R}\left[50,0^{\circ} \mathrm{C}\right]$ a $45,0^{\circ} \mathrm{R}$ $\left[56,25^{\circ} \mathrm{R}\right]$ y muestra igualmente un ligero sabor salado. Esta fuente es visitada frecuentemente por el ganado vacuno. En los sitios ubicados al oeste de las fuentes principales, se deposita poco carbonato, la temperatura alcanza aquí de $50,0^{\circ} \mathrm{R}$ $\left[62,5^{\circ} \mathrm{C}\right]$ a $53,0^{\circ} \mathrm{R}\left[66,25^{\circ} \mathrm{C}\right]$ y muestra igualmente un ligero sabor salado. Restos de conos calcáreos quebrados indican que estas fuentes tenían anteriormente un caudal más alto y que depositaban más carbonato. El color ocre café oscuro alrededor de los agujeros por donde sale el agua demuestra un ligero contenido de hierro.

La sal depositada en las fuentes principales no muestra ningún indicio de sal gema o algún otro compuesto de cloruros, sino que casi solamente se presentan compuestos como sulfato de sodio y carbonato de sodio.

Dicen que aproximadamente a una distancia de 800 pasos agua abajo, aparecen más manantiales calientes y donde se formó un salitral.

10. En la margen izquierda del río Altarrazú, un poco más abajo del lugar donde se une con el río Candelaria, se encuentra una fuente termal tibia a los pies del cerro Bustamante, en el lado norte del mismo cerca del poblado Los Frailes, ubicada en la finca del fallecido Santos León.

11. Igualmente existe una fuente termal caliente de $29,3{ }^{\circ} \mathrm{R}\left[36,6^{\circ} \mathrm{C}\right]$, en la vertiente sur del cerro mencionado anteriormente, precisamente en la margen derecha del río Parrita, a 1000 pasos de donde se encuentran las casas de habitación, del poblado Boca Dota. Un manantial frío de agua dulce que surge cercano a la fuente termal muestra solamente una temperatura de $13,6^{\circ} \mathrm{R}[17,0$ $\left.{ }^{\circ} \mathrm{C}\right]$, la cual se acerca a la temperatura promedio del área. El agua de la fuente termal no muestra ningún sabor a sal, sin embargo vienen ciervos y tapires, así como el ganado que pasta en las cercanías para beber del agua estancada.

12. Hacia el occidente de la fuente 10 , en el río Tarrazú, se encuentran en la margen izquierda del río Grande, igualmente al pie del cerro Bustamante, muchas fuentes termales, cuya agua se acumula como agua estancada, a las cuales se les da el nombre de Salitral del Rayo.

13. A Una legua de distancia río abajo fluye cerca del río una fuente termal con fuertes emanaciones sin formar un salitral y desemboca inmediatamente en el río Grande, llamándose Agua Caliente del Cangrejal.

14. En la vertiente sur de la cadena montañosa que da lugar a la divisoria de aguas entre el Valle de Pacaca y el río Grande de Pirrís, aparecen en las cercanías de la localidad de Puriscal, un poco al sur de San Rafael, en una garganta fluvial del río Viejo, dos manantiales de agua caliente 
con tan elevada temperatura, que se puede cocinar un huevo dentro de ella. Dicen que en las cercanías se encuentran sal gema y alumbre [N.T. en el sentido estricto se denomina alumbre al sulfato doble de aluminio y potasio $\left.\mathrm{AlK}\left(\mathrm{SO}_{4}\right)_{2} 12 \mathrm{H}_{2} \mathrm{O}\right]$.

15. A los pies del Cerro Dota, en el lugar conocido como Hato Viejo, a una distancia de 4 leguas de la localidad de Térraba, se encuentran en una garganta fluvial, la cual se abre hacia el valle de Hato Viejo, de tres a cuatro fuentes termales, y aguas abajo, pero antes de que la garganta se abre al valle, aparece un Salitral. También, en este lugar se producen gases, su grado de calor es de tal magnitud, que la mano se puede mantener en el agua solamente durante un corto tiempo. Dicen que en las cercanías se encuentran depósitos calcáreos.

16. Más hacia el este existe otra fuente termal, sobre la falda norte del cerro Pico Blanco, en el Valle del río Uren, un afluente del Sixaola en las cercanías del pueblo indígena Bribri.

El tercer grupo de fuentes termales se encuentra al noroeste de las anteriormente mencionadas, en parte sobre las laderas meridionales del Cerro del Aguacate y en parte a los pies de la cordillera que se extiende desde Esparza hasta Guanacaste.

17. La fuente termal más oriental de este grupo, es una fuente que se encuentra en la confluencia de los ríos Virilla con el río Grande en cuyas cercanías se encuentra también un salitral.

18. Continuando corriente abajo en el Paso del Alumbre, donde el río separa a los poblados de Santo Domingo y San Pablo, aparecen en ambas orillas del río, pero principalmente en la derecha una cantidad de fuentes calientes, de las cuales la más caliente tenía $52,8^{\circ} \mathrm{R}\left[66,0^{\circ} \mathrm{C}\right]$ y otra $48,2^{\circ} \mathrm{R}[60,3$ ${ }^{\circ} \mathrm{C}$ ] y la que se ubica en la orilla izquierda tenía solo $35^{\circ} \mathrm{R}\left[43,8^{\circ} \mathrm{C}\right]$. El ganado llega de las cercanías a lamer los bloques rocosos cubiertos de sal. La orilla rocosa del río se compone de rocas porfiríticas.

19. En uno de los mapas ingleses de navegación, publicado por la oficina Hidrográfica, denominada Centralamerica; Westcoast, 1838 y 1840, hoja IV, se mencionan manantiales calientes (hot springs) en el puerto de Caldera, directamente en la orilla del mar, en la ladera norte de un pequeño cerro.

20. En las nacientes del río Machuca en los Montes del Aguacate, 11/4 leguas hacia el norte de San Mateo en la margen de la quebrada Yurro
Amarillo, hay varias fuentes termales, en cuyas cercanías se deposita sal gema. Aquí se encuentran también importantes masas calcáreas en forma de travertino, las cuales son explotadas por medio de una cantera. También aparece aquí salitre y manganeso.

21. Dos leguas al Norte de Esparza en la margen del río Barranca se encuentra una fuente termal, llamada Agua Caliente de la Trinchera porque se encuentran muros de piedras constituidos anteriormente por los aborígenes de la zona.

En la margen derecha del brazo oriental del río Barranca, un cuarto de legua hacia arriba de la unión con el brazo occidental, se encuentran al pie de un cerro de rocas porfiríticas depósitos de travertino los cuales se extienden en el río. Aproximadamente a 20 pasos de distancia de la orilla se encuentran en un lugar pantanoso unos conos pequeños de 3 a 4 pies de altura compuestos de una masa calcárea de color blanco, en cuyo ápice de color amarillo ocre surge periódicamente agua caliente con generación de gases, lo cual provoca paulatinamente el aumento de tamaño de los conos. En los alrededores también brota en diferentes puntos agua caliente del piso. La temperatura de esta agua, la cual tiene un ligero sabor salado alcanzaba en un lugar $55,6^{\circ} \mathrm{R}\left[69,5^{\circ} \mathrm{C}\right]$, en otros solo $40,0^{\circ} \mathrm{R}\left[50,0^{\circ} \mathrm{C}\right]$ hasta $48^{\circ} \mathrm{R}\left[60,0^{\circ} \mathrm{C}\right]$. Esta es, por lo tanto, la fuente termal más caliente que he conocido en Costa Rica. En muchos lugares las rocas están cubiertas con cristales de sal, principalmente cerca de las salidas del agua caliente, por lo cual también son aprovechados por el ganado vacuno y los animales del bosque para consumir la sal.

22. En el Golfo de Nicoya, se presentan algunas fuentes termales a los pies de un acantilado, que se forma por las colinas conocidas como cerros Pájaro y Coyolito precisamente donde el pequeño río La Palma se une con el río Abangares.

23. A algunas leguas al este de la ciudad de Cañas en la provincia de Guanacaste, se encuentran cerca de las nacientes del río Abangares algunas fuentes calientes y yacimientos de salitre (ver la Gaceta oficinal de Costa Rica, No. 111 [N.T. Lo correcto es la número 11], junio 1 de 1861).

24. A un tercio de Legua de Bagaces en Guanacaste aparecen varias fuentes termales y 
muy cerca se encuentra un salitral de considerable extensión.

25. Dicen que al oeste de la pequeña ciudad de Liberia, en la misma provincia de Guanacaste, se encuentra una fuente termal en la hacienda la Cueva.

Considero que esta contribución sobre las fuentes termales de Costa Rica está incompleta y tenía muchos deseos de ampliar mis investigaciones, pero lastimosamente no me fue posible realizarlas. Sin embargo, me parece importante publicar las investigaciones ya que podrían ser un estímulo para otras personas que están interesadas en este tema y que encuentren mejores condiciones para continuar con las investigaciones que empecé. Para viajeros interesados en las ciencias que en el futuro lleguen a Costa Rica para estudiar los fenómenos de la naturaleza de este país, que son tan poco conocidos, estas notas podrían servir de referencia.

\section{DISCUSIÓN}

El manuscrito presentado por von Frantzius en 1862 en forma de libro constituye el primer catálogo de fuentes termales ya que constituye una memoria y un listado de fuentes termales. Aunque en el mismo año salió publicado un artículo sobre fuentes termales (Frantzius, 1862a) y se presentó como traducción de von Frantzius (2007a), este carece de la descripción de seis fuentes termales, las cuales sí son descritas en el libro. En el libro se presenta una descripción ordenada en tres grupos de fuentes por ubicación geográfica. El primer grupo lo constituyen las fuentes ubicadas al sur de Cartago y cerca de Desamparados y de Tres Ríos. El segundo grupo lo forman las fuentes del Río Grande y Candelaria. Aquí incluye las fuentes ubicadas al sur del país y el tercer grupo de fuentes termales se encuentran al noroeste de estas fuentes indicadas anteriormente en las laderas meridionales de los cerros del Aguacate y de la cordillera de Guanacaste. Entre 1756 a 1858 se encuentran las primeras referencias por escrito de las fuentes termales en Costa Rica, iniciando el primer reporte escrito en el año 1756, cuando dos misioneros mencionan en sus crónicas la existencia de un yacimiento de sal, asociado a una fuente termal, ubicada al norte de Esparza en dirección hacia la cordillera (von Frantzius, 2007a y 2007b).

Posteriormente, durante la época colonial y la fundación de la ciudad de Cartago como capital, surge información sobre la fuente termal de Aguacaliente de Cartago, ya que al parecer los españoles confeccionaron un muro alrededor de dicha fuente (Platt, 1865), del cual desdichadamente quedan pocos vestigios. Más adelante varios exploradores extranjeros como por ejemplo el inglés John Hale (1826) comenta sobre la fuente termal de Aguacaliente de Cartago. Se habla por primera vez de los posibles aspectos curativos de alguna de las fuentes termales, principalmente la de Aguacaliente de Cartago y es mencionada también por Thomas Francis Meagher (1886) y por Wilhem Marr (1863) en los viajes que realizó.

Como se desprende de lo anterior los españoles investigaron las propiedades de las fuentes termales de una manera muy escueta, sin rigurosidad científica, dejando un gran vacío de conocimiento en más de 200 años, hasta que se iniciaron las primeras investigaciones en la segunda mitad del siglo XIX con la llegada de inmigrantes del norte de Europa y se realizan las primeras descripciones geológico-mineralógicas y geoquímicas generales, su temperatura, así como los primeros catálogos propiamente dichos.

\section{AGRADECIMIENTOS}

Agradecemos el apoyo recibido por la señora Martha Rosen del Instituto Smithsoniano en Washington, por localizar y enviar el documento original guardado en el fondo especial de la Biblioteca del Congreso.

\section{REFERENCIAS BIBLIOGRÁFICAS}

ARIAS, O. \& DENYER, P., 1990a: Geología de la hoja Caraigres.- Instituto Geográfico Nacional. Escala 1: 50 000. San José.

ARIAS, O. \& DENYER, P., 1990b: Geología de la hoja Río Grande.- Instituto Geográfico Nacional. Escala 1: 50 000. San José. 
ARIAS, O. \& DENYER, P:, 1991: Estructura geológica de la región comprendida en las hojas topográficas Abra, Caraigres, Candelaria y Río Grande, Costa Rica. Rev. Geol. Amér. Central, 12: 61-74.

FAILLACE, C., 1973: Notas sobre algunas fuentes termominerales en Guanacaste.- Publicaciones Geológicas del ICAITI, IV: 47-58.

HALE, J., 1826: Six months residence and travels in Central America, through the free states of Nicaragua and particularly Costa Rica.32 págs. Edit. W. Borradaile, New York.

MARR, W., 1863: Viaje a Centroamérica (Traducido por Reinhold, I. [2004]).- 472 págs. Ed. Univ. Costa Rica, San José.

MEAGHER, T., 1886: Aguas Termales de Cartago.73 págs. Imprenta José Canalías. San José.

MONTERO, W., 1993: Mapa sismológico y neotectónico de la gran área metropolitana.Escala 1: 200 000.- En: P. Denyer \& S. Kussmaul (eds): Atlas geológico Gran área metropolitana.- Ed. Tecnológica de Costa Rica. Cartago.

MONTERO, W. 2003: El sistema de falla Atirro-Río Sucio y la cuenca de tracción de TurrialbaIrazú: indentación tectónica relacionada con la colisión del levantamiento del Coco.- Rev. Geol. Amér. Central, 28: 5-29.

PANiAGUA, S., 2000: Aguas termales.- En: P. Denyer \& S. Kussmaul, S. (eds.): Geología de Costa Rica.- Ed. Tecnológica de Costa Rica, Cartago: 443-455.

PLATT, L., 1865: Examen analítico de cuatro fuentes de agua mineral de Costa Rica.- La Gaceta oficial del 23 de setiembre de 1865 [Reproducción en GONZÁLEZ, C., 1910:
Temblores, terremotos, inundaciones y erupciones en Costa Rica, San José, 113].

SAENZ. R., 1971: Aparatos volcánicos y fuentes termales de Costa Rica.- Dirección de Geología, Minas y Petróleo, Informes Técnicos y Notas Geológicas, 41: 1-16.

SAENZ. R. \& BARQUERO, J., 1983: Fuentes termominerales de Costa Rica.- Bol. Vulcanol. 13: 13-16.

VON FRANTZIUS, A., 1861: Beiträge zur Kenntniss der Vulkane Costa Rica's (Traducción U. Rehaag. Antología El Volcán Poás).- Ed. UNED, San José: 1133.

VON FRANTZIUS, A., 1862a: Die warmen Mineralquellen in Costa Rica (Schluss).Preussische Medizinalzeitung, 14-16: $124-$ 126.

VON FRANTZIUS, A., 1862b: Die warmen Mineralquellen in Costa Rica.- 16 págs. Edit. A. W. Schade, Berlin.

VON FRANTZIUS, A.,2007a: Las fuentes termominerales en Costa Rica I. [traducido por A. Vargas \& S. Kussmaul del original del año 1873].- Rev. Geol. Amér. Central, 37: $23-30$.

VON FRANTZIUS, A.,2007b: Las fuentes termominerales en Costa Rica II. [traducido por A. Vargas \& S. Kussmaul del original del año 1862].- Rev. Geol. Amér. Central, 37: $31-34$.

VON SEEBACH, K., 1865: Reise nach Guanacaste.- Mittheilungen aus Justus Perthes Geographischer anstalt über wichtige neue erforschungen auf dem gesamtgebiet der Geographie, 7: 241-247. 